\title{
Budaya suku Lembak mempengaruhi perencanaan karier siswa
}

Heni Sulusyawati $\left.1^{*}\right)$, Syamsuddin ${ }^{2}$

Universitas Prof. Dr. Hazairin, $\mathrm{SH}^{123}$

*) Alamat korespondensi: Jl. Jend. A. Yani No. 1, Bengkulu, 38115, Indonesia; E-mail: henisulusyawati9@gmail.com

Article History:

Received: 09/02/2021;

Revised: 23/02/2021.

Accepted: 25/02/2021;

Published: $28 / 02 / 2021$.

How to cite:

Sulusyawati, H. \& Syamsuddin. (2021). Budaya suku Lembak mempengaruhi perencanaan karier siswa. Teraputik: Jurnal Bimbingan dan Konseling, 4(3), pp. 460-470. DOI: 10.26539/teraputik-43564

\begin{abstract}
Abstrak: Adanya siswa di Lembak yang mengalami kebingungan dalam memilih jurusan di perguruan tinggi. Hal ini menjadi tujuan penelitian untuk mendeskripsikan pengaruh budaya Lembak terhadap perencanaan karier siswa. Jenis penelitian merupakan deskriptif kualitatif natural setting. Teknik pengumpulan data menggunakan teknik observasi partisipatif, wawancara tak terstruktur, dan dokumentasi. Analisis data menggunakan model Spradley analisis domain, taksonomi, komponensial, \& tema kultural. Analisis domain menghasilkan data bahwa perencanaan karier siswa kurang optimal. Analisis taksonomi, menghasilkan data perincian peran orang tua, kedisiplinan, komunikasi, dan tanggung jawab. Analisis komponensial, orang tua hanya memberi kecukupan materi, sementara bimbingan terhadap anak kurang. Analisis tema kultural, perencanaan karier siswa kurang optimal karena kurangnya peran orang tua sebagai bagian dari akibat perilaku kultural. Komunikasi siswa yang kasar menyebabkan relasi pertemanan siswa di Lembak terbatas. Jadi, pada budaya Lembak 1) orang tua kurang berperan, 2) siswa kurang disiplin, 3) pergaulan terbatas, dan 4) siswa kurang bertanggung jawab mempengaruhi perencanaan karier siswa.
\end{abstract}

Kata Kunci: Perencanaan Karier, Budaya Lembak

Abstract: There are students in Lembak who experience confusion in choosing majors in higher education. This is the research objective to describe the influence of Lembak culture on student career planning. This type of research is a descriptive qualitative natural setting. Data collection techniques using participatory observation techniques, unstructured interviews, and documentation. Data analysis used Spradley's model of domain analysis, taxonomy, components, \& cultural themes. Domain analysis yields data that students' career planning is less than optimal. Taxonomic analysis, producing detailed data on parental roles, discipline, communication, and responsibilities. Componential analysis, parents only provide material adequacy, while guidance for children is lacking. Analysis of cultural themes, student career planning is not optimal because of the lack of the role of parents as part of the consequences of cultural behavior. Rough student communication causes student friendships in Lembak to be limited. So, in Lembak culture 1) parents do not play a role, 2) students lack discipline, 3) limited social relationships, and 4) students are not responsible for influencing student career planning.

Keywords: Career Planning, Lembak Culture

\section{Pendahuluan}

Siswa diharapkan dapat mengikuti tahap perkembangan karier ketika di bangku SMA sesuai dengan tahap perkembangan karier yang ada. Hal ini ditujukan agar ketika tamat SMA, siswa sudah memiliki arah perencanaan karier yang matang. Siswa dikatakan sudah memiliki perencanaan karier yang matang apabila siswa dapat memahami potensi dirinya, mendapatkan informasi dunia kerja dan siswa mampu mencocokkan diri dengan informasi dunia kerja yang ada.

Super (dalam Sharf, 2010) mengemukakan bahwa perkembangan karier siswa dibagi dalam beberapa tahapan, yaitu: 1) pertumbuhan; sejak lahir sampai sebelum usia lima belas tahun dalam tahap pertumbuhan ini individu mengembangan berbagai potensi pandangan khas perilaku dan minat individu, 2) eksplorasi; dalam tahap ini diperkirakan usia anak lima belas tahun sampai dua puluh lima tahun. Dalam masa ini individu mulai memikirkan alternatif karier, tetapi belum dapat mengambil keputusan, 3) pendirian; dalam fase ini di mulai dari usia dua puluh lima tahun sampai empat puluh lima tahun. Pada fase ini individu mulai dapat memantapkan diri 
berdasarkan beberapa pengalaman, 4) manajemen; dalam tahap ini dimulai dari usia empat puluh lima tahun sampai enam puluh lima tahun. Pada fase ini individu mulai dapat menyesuaikan diri dan mulai penghayatan jabatan, 5) pelepasan; dalam tahap ini individu berada pada usia enam puluh lima tahun, dalam fase ini individu sudah mulai memasuki masa pensiun.

Perencanaan karier sejak masih duduk di bangku sekolah sangat penting. Perencanaan karier yang baik mengarah pada pemenuhan hidup yang baik pula (Akosah-Twumasi et al., 2018). Zar (dalam Salleh, et al. 2020) mengemukakan perencanaan karier bertujuan untuk mengidentifikasi kebutuhan, aspirasi, peluang bagi individu terakit karier dan pelaksanaan program pengembangan sumber daya manusia untuk mendukung karier tersebut.

Desimone (dalam Kaswan, 2014) mengemukakan perencanaan karier siswa merupakan 1) kesadaran diri dan konsekuensinya, 2) penentuan tujuan yang berhubungan dengan karier, dan 3) pekerjaan pemrograman, pendidikan, pengalaman dan pengembangan terkait untuk memberikan bimbingan untuk mencapai tujuan karier. Berdasarkan pendapat para ahli yang dijelaskan sebelumnya, dapat disimpulkan bahwa perencanaan karier merupakan proses penyelarasan diri dan lingkungan, meliputi: 1) pemahaman diri yang meliputi aspek kemampuan intelektual, bakat, minat, kelebihan dan kelemahan diri, serta pengetahuan, 2) pengetahuan tentang dunia kerja, meliputi syarat-syarat suatu pekerjaan, kondisi yang mendukung keberhasilan pekerjaan, keuntungan \& kerugian suatu pekerjaan, dan 3) pencocokkan diri dengan pengetahuan tentang dunia kerja.

Heer, E. L., Cramer, s. H., \& Niles, (2004) mengemukakan beberapa pertimbangan pentingnya perencanaan karier siswa Pendidikan Menengah Atas. Pertimbangan tersebut, antara lain: banyaknya siswa, penekanan bimbingan karier komprehensif, teknik dalam mencari pekerjaan, dan keterampilan dan wawasan. Siswa mengalami tekanan internal \& eksternal dalam mengambil keputusan untuk memasuki perguruan tinggi. Ada kebingungan apakah mau kuliah lanjutan, bekerja, mengabdi militer, atau melamar di pegawai pemerintahan. Beberapa pertimbangan tersebut dapat dijadikan dasar pentingnya siswa mempersiapkan perencanaan karier sejak dini.

Dunia pendidikan merupakan proses awal dalam perencanaan karier siswa. Meskipun belum berencana langsung bekerja, pendidikan membantu siswa mengenal potensinya. Pendidikan menyediakan informasi terkait dengan perkembangan karier kepada siswa. Karena sekecil apapun informasi karier yang didapat oleh siswa sangat berharga untuknya dalam mempersiapkan perencanaan karier ke depan Yusuf, (2002).

Namun, masih terdapat siswa-siswi yang belum memikirkan perencanaan karier ke depannya. Bahkan, sering kali siswa-siswi pada saat duduk di tingkat Sekolah Menengah Atas (SMA) kurang peduli terhadap perencanaan karier yang cocok dengan potensi dirinya. Pada siswa-siswi SMA Negeri 3 Palembang perencanaan karier siswanya masih terdapat $17,36 \%$ siswa memiliki kategori rendah dan 7,25\% siswa memiliki kategori sangat rendah dalam merencanakan karier (Kurniasari et al., 2016). Selain itu, hal yang sama juga terlihat pada SMA $\mathrm{N} 1$ Kubu Rokan Hilir dengan gejala yang ditunjukkan terhadap perencanaan karier siswa, lima belas dari tiga puluh orang siswa mengaku tidak mengetahui rencana kariernya ke depan (Julia \& Afandi, 2020). H. Sulusyawati et al., (2017) menunjukkan bahwa perencanaan karier siswa secara keseluruhan tergolong sedang, masih ditemukannya dalam indikator perencanaan karier yang tergolong rendah,

Berdasarkan studi pendahuluan yang telah dilakukan, ditemukan siswa-siswi yang budaya Lembak masih banyak yang kurang disiplin, sering datang ke sekolah terlambat. Ketika Guru mengajak untuk komunikasi mereka lebih banyak diam. Ada juga yang menjawab, tetapi dengan jawaban yang kurang sopan dilontarkan oleh siswa terhadap guru. Siswa yang budaya Lembak lebih suka bermain di luar kelas dibandingkan mengikuti kegiatan KBM di sekolah. Contohnya, pada saat jam istirahat, sudah habis bel masuk sudah berbunyi, mereka belum bergegas masuk ke kelas. Mereka lebih suka masuk ke kelas bersamaan dengan guru masuk ke kelas.

Apabila perilaku-perilaku seperti dijelaskan sebelumnya terus berkembang dalam diri siswa, akan sangat berpengaruh terhadap perkembangan diri siswa ke depannya, khususnya dalam mempersiapkan perencanaan karier ke depan, memasuki Perguruan Tinggi atau memasuki dunia kerja. 
Selanjutnya, H. \& J. Sulusyawati, (2019) menunjukkan adanya pengaruh budaya Serawai terhadap perencanaan karier siswa, meliputi penurut, rajin, keinginan yang tinggi, dan hemat. Siswa dari suku budaya Rejang memiliki perencanaan karier yang cukup baik, tetapi masih terdapat dalam indikator perencanaan karier yang masih tergolong rendah. $(\mathrm{H}$. Sulusyawati \& Sari, 2019). Sulusyawati \& Melati, (2019) mengemukakan adanya beberapa faktor pengaruh budaya rejang terhadap perencanaan karier siswa, yaitu 1) kebiasaan orang tua dalam mengambil keputusan untuk anaknya, 2) pengaruh teman sebaya, 3) menunda-nunda pekerjaan, 4) keinginan dan semangat yang tinggi untuk maju. Pada hasil penelitian dari $\mathrm{H}$. Sulusyawati \& Juwanto, (2020) menunjukkan bahwa pengaruh budaya serawai terhadap perencanaan karier siswa, yaitu 1) penurut, 2) rajin, 3) keinginan yang tinggi, 4) hemat.

Berdasarkan beberapa teori yang diuraikan sebelumnya, salah satu faktor penentu perencanaan karier adalah budaya. Provinsi Bengkulu kaya akan budaya, Terdapat sembilan suku di Provinsi Bengkulu yaitu suku Serawi, suku Lejang, suku Melayu, suku Ngano, suku Mukomuk, suku Pasma, suku Kaur \& suku Lumbak (Mahdi et al., 2019;Fauziyah et al., 2020; Kurnia et al., 2020; Refisrul, 2019). Suku Lembak adalah bagian dari masyarakat Bengkulu (Hajad \& Nanik, n.d.). Di Provinsi Bengkulu, suku Lumbak hidup di beberapa daerah, yaitu Kabupaten Rejang Lebong, Kabupaten Bengkulu Tengah (Benteng) dan Kota Bengkulu. Suku Lembak yang tinggal di Kabupaten Rejang Lebong disebut suku Beliti. Sementara suku Lembak yang tinggal di Kabupaten Bengkulu Tengah dan Kota Bengkulu disebut suku Lembak delapan yang dibagi dalam tiga suku, yaitu suku Lembak, Tanjung Agung, dan Suku Lembak Pedalaman.

Suku Lembak Delapan memiliki satu kerajaan tua di Bengkulu, yaitu Sungai Serut, berada di daerah Tanjung Terdana dan menyebar di sepanjang sungai Bangkahulu. Kerajaan Sungai Serut berasal dari sungai yang disebut Sungai Serut. Suku Lembak awalnya bermukim di daerah Padang Ulak Tanding yang terletak di pinggiran Kerajaan Rejang Lebong Empat Petulai, dari daerah Padang Ulak Tanding dan Lubuk Linggau, dan akhirnya menyebar ke kota Bengkulu. Suku Lembak yang tinggal di daerah Bengkulu menyebar di berbagai Kecamatan dan Kelurahan yaitu Kecamatan Selebar; Kelurahan Pekan Sabtu, Sukarami, Pagar Dewa, Kecamatan Gading Cempaka; Kelurahan Jalan Gedang, Sidomulyo, Kecamatan Singaran Patih; Keluran Dusun Besar, Panorama, Jembatan Kecil, Kecamatan Sungai Serut; Kelurahan Tanjung Agung, Tanjung Jaya, Semarang, Surabaya, dan Kecamatan Muara Bangkahulu; Kelurahan Bentiring.

Masyarakat suku Lembak dalam menjalani kehidupan sehari-hari masih banyak tradisi atau kebiasaan lama yang masih dipedomani dan dilakukan seperti tradisi upacara daur hidup (lahir sampai meninggal). Contohnya, adat istiadat perkawinan, membuang rambut cemar dan aqiqah, serta kerajinan tradisional seperti Kesenian Sarafal Anam. Masyarakat suku Lembak seperti masyarakat Bengkulu pada umumnya pemeluk Agama Islam, begitu juga dengan budayanya banyak yang bernuansa Islam. SMA Negeri 9 Kota Bengkulu terletak di Kecamatan Muara Bangkahulu Kelurahan Bentiring. Siswa-siswi SMA Negeri 9 Kota Bengkulu berasal dari berbagai ragam budaya, yaitu suku Serawai, Melayu, Rejang, Pasmah dan Lembak. Namun, suku yang lebih dominan adalah budaya Lembak.

Banyak faktor yang mempengaruhi perencanaan karier siswa, baik faktor internal, maupun faktor eksternal. Shertzer \& Stone (dalam W.S, Winkel \& Hastuti, 2013) menguraikan ada dua faktor yang mempengaruhi. Faktor tersebut, yaitu: 1) Faktor internal meliputi nilai kehidupan, tingkat intelektual, bakat khusus, minat, sifat, pengetahuan, dan kondisi fisik; 2) Faktor eksternal, meliputi masyarakat, keluarga, status ekonomi, asosiasi sekolah, teman sebaya, dan jabatan. Aminurrohim et al., (2014) mengemukakan banyak faktor eksternal perencanaan karier yang dipengaruhi oleh kondisi sekolah. Pemangku pendidikan memiliki peran penting, terutama dalam pembentukan karakter dan perencanaan karier siswa (Hanggara, 2016; Masaong, 2012; Prasetiawan, 2016; Subianto, 2013).

Untuk mewujudkan agar siswa memiliki perencanaan karier yang matang setelah tamat SMA, tentu tidak lepas juga dari peran Guru Bimbingan Konseling di sekolah. Aspek yang sangat penting untuk dikembangkan adalah kemampuan memahami potensi diri, mengenal berbagai informasi dunia kerja, dan siswa mampu menyesuaikan antara potensi diri yang dimiliki dengan informasi dunia kerja yang ada. Ahmad (2013) mengemukakan bahwa perencanaan karier tentu saja dimulai sejak individu di bangku sekolah. Pelayanan bimbingan konseling seyogyanya dapat memberikan layanan dengan menyediakan berbagai peluang karier oleh siswa. 
Berdasarkan literatur dari jurnal-jurnal penelitian yang ada, belum ada penelitian tentang pemaparan bagaimana budaya suku Lembak di Indonesia, terhadap perencanaan karier siswa. Penelitian tentang pengaruh budaya pada faktor penentu karier (Gunkel et al., 2013). Bagaimana budaya mempengaruhi karier pada mahasiswa pascasarjana (Haley et al., 2014), pada konteks pedesaan di Virginia (Carrico et al., 2019), pada konteks tenaga perawat di Melbourne, Australia (Gower et al., 2018), pada semangat remaja di Amsterdam, Netherlands (Andre et al., 2019), pada budaya Kanada (Arthur \& Flynn, 2011), pada budaya Queensland, Australia (Robinson et al., 2016), dan pada konteks siswa yang sekolah praktik di Carolina Selatan (Mobley et al., 2017). Penelitian variabel karier dengan budaya di Indonesia masih sedikit. Pada budaya lain, $(\mathrm{H}$. \& J. Sulusyawati, 2019; H. Sulusyawati \& Juwanto, 2020) meneliti pengaruh budaya suku Serawai terhadap perencanaan karier siswa, dan budaya suku rejang terhadap karier $(\mathrm{H}$. Sulusyawati \& Sari, 2019). Hal ini menunjukkan adanya kekosongan penelitian dalam konteks pengaruh budaya suku Lembak terhadap perencanaan karier siswa.

Rumusan penelitian adalah "Bagaimana pengaruh budaya Lembak terhadap perencanaan karier siswa?" Tujuan penelitian adalah untuk mendeskripsikan data tentang pengaruh budaya Lembak terhadap perencanaan karier siswa. Manfaat hasil penelitian diharapkan dapat membantu menyediakan data tentang perencanaan karier siswa dan dapat membantu guru Bimbingan Konseling dalam mematangkan perencanaan karier siswa, khususnya siswa budaya Lembak.

\section{Metode}

Jenis penelitian ini yaitu penelitian deskriptif kualitatif menggunakan pendekatan dalam konteks natural setting (Sugiyono, 2018), yaitu pendekatan yang lebih memahami fenomena apa yang yang dialami oleh subyek penelitian. Adapun yang menjadi lokasi penelitian yaitu di SMA Negeri 9 Kecamatan Muara Bangka Hulu Kota Bengkulu. Dasar pertimbangan pemilihan lokasi penelitian di SMA Negeri 9 Kota Bengkulu karena siswa-siswi di sekolah ini memiliki latar belakang budaya yang beragam. Penelitian dilakukan sejak Juli 2019 hingga Januari 2021, kurang lebih membutuhkan waktu selama satu setengah tahun dari studi literatur hingga penyusunan laporan.

Pengambilan sampel teknik purposive sampling (Sugiyono, 2018). Subyek dalam penelitian ditentukan berdasarkan karakteristik siswa-siswi yang memiliki latar belakang budaya Lembak yang berjumlah sepuluh orang siswa, terdiri dari lima orang siswa laki-laki \& lima orang siswa perempuan.

Pengumpulan data dilakukan dengan cara observasi, wawancara, dan dokumentasi. Observasi yang digunakan yaitu observasi partisipatif yang pasif, tidak ikut terlibat. Selanjutnya, wawancara tidak terstruktur, tanpa pedoman wawancara sistematis, hanya berupa garis besar. Dokumentasi yang mendukung, seperti foto atau karya tulis akademik \& seni yang dimiliki oleh informan.

Analisis data menggunakan model Spradley (Sugiyono, 2018). Menurut Spradley ada empat tahapan analisis data penelitian kualitatif, yaitu analisis domain, analisis taksonomi, analisis komponensial, \& analisis tema kultural. Tahap analisis domain menguraikan gambaran umum \& menyeluruh obyek yang diteliti. Tahap analisis taksonomi berdasarkan analisis domain, menguraikan lebih rinci untuk mengungkap struktur internalnya. Tahap analisis komponensial, menguraikan ciri setiap struktur dengan mengkontraskan elemen yang ada. Terakhir, tahap analisis tema kultural menguraikan hubungan domain keseluruhan. 


\section{Hasil dan Diskusi}

Pembahasan hasil dan diskusi menguraikan temuan hasil analisis domain, taksonomi, komponensial, \& tema kultural. Selanjutnya, diuraikan diskusi pembahasan penelitian terkait dengan pengaruh Budaya Lembak terhadap pengaruh perencanaan karier siswa. Hasil temuan diuraikan pada Tabel 1. Hasil Analisis Data berikut.

Tabel 1. Hasil Analisis Data

\section{Analisis Domain}

Adapun indikator perencanaan karier ini meliputi pemahaman diri, pengetahuan tentang dunia kerja, dan pencocokkan diri \& pengetahuan tentang dunia kerja. Berdasarkan indikator tersebut, hasil analisis domain pada siswa budaya Suku Lembak membuktikan bahwa ratarata siswa belum memikirkan rencana karier yang diinginkan ke depan. Hal ini tampak pada pemahaman diri yang kurang, pengetahuan dunia kerja yang kurang, pencocokan diri \& pengetahuan tentang dunia kerja juga kurang. Jika diihat dari keseharian latar belakang budaya Lembak, orang-orang cenderung berkelompok berdasarkan budaya Lembak. Hal ini pun berlaku pada siswa. Siswa kurang bisa berbaur dengan siswa yang lain. Siswa budaya Lembak merasa kurang diperhatikan oleh orang tua. Orang tua hanya fokus mencari nafkah untuk kebutuhan keluarga. Orang tua tidak memiliki waktu untuk diskusi tentang perencanaan karier anaknya. Siswa juga kurang disiplin dalam mengikuti tata tertib di sekolah. Ketika berkomunikasi dengan guru siswa kurang sopan, begitu juga dengan teman sebaya. Rata-rata siswa kurang bertanggung jawab terhadap tugas. Selain itu, siswa juga kurang memiliki pendirian yang teguh karena siswa mudah dipengaruhi oleh teman sebaya.

\section{Analisis Taksonomi}

Berdasarkan analisis domain, dapat dikemukakan beberapa faktor dari kebiasaan siswa budaya Lembak yang dapat mempengaruhi perencanaan karier siswa, di antaranya peran orang tua, kedisiplinan, komunikasi, dan tanggung jawab. Berdasarkan analisis keempat faktor tersebut dapat mempengaruhi perencanaan karier siswa.

Analisis Komponensial

Berdasarkan analisis taksonomi yang diuraikan sebelumnya, dalam analisis komponensial dapat diuraikan beberapa faktor budaya Lembak yang mempengaruhi perencanaan karier siswa. Budaya tersebut, antara lain: 1) peran orang tua; 2) kedisiplinan; 3) komunikasi; 4) tanggung jawab. Pada faktor peran orang tua, siswa budaya Lembak kurang mendapatkan perhatian dan dukungan dari orang tua dalam melakukan perencanaan karier. Orang tua cenderung menyediakan biaya pendidikan saja. Orang tua tidak ingin tahu jurusan apa yang anaknya ambil. Bahkan, orang tua kurang menyediakan waktu diskusi dengan anaknya. Sementara pada saat siswa mempersiapkan perencanaan karier sangat penting adanya masukkan dan saran dari orang tua. Mengingat orang tua yang jauh lebih memahami potensi yang ada pada anak. Faktor yang kedua, yaitu kedisiplinan. Siswa budaya Lembak cenderung kurang disiplin pada saat di lingkungan sekolah. Hal ini tampak dari siswa-siswi sering datang terlambat. Ketika guru BK mengajak untuk diskusi tentang dengan perencanaan karier, siswa sering tidak mengikuti. Faktor yang ketiga, yaitu komunikasi. Siswa budaya Lembak kurang mampu menjalin komunikasi yang baik, baik dengan guru maupun dengan teman. Kebiasaan siswa berkomunikasi dengan tutur sapa yang kasar, sehingga membuat teman-teman di sekolah yang bukan dari suku budaya Lembak kurang mau bergaul. Faktor keempat, yaitu tanggung jawab. Siswa budaya Lembak mayoritas kurang bertanggung jawab dalam mengerjakan tugas-tugas yang diberikan oleh Guru.

$$
\text { Analisis Tema Kultural }
$$

Berdasarkan analisis komponensial, dapat dikemukakan faktor-faktor budaya Lembak yang dapat mempengaruhi perencanaan karier siswa, yaitu: peran orang tua, kedisiplinan, komunikasi, dan tanggung jawab. Faktor pertama, peran orang tua. Siswa budaya Lembak merasa kurang mendapat perhatian dari orang tua. Orang tua tidak meluangkan waktu untuk 
berdiskusi dengan anak terkait dengan perencanaan karier, orang tua hanya menyiapkan dana pendidikan saja, tanpa mau tahu jurusan apa yang dipilih oleh anak, apakah jurusan yang dipilih atau karier yang diinginkan anak cocok dengan potensi diri anaknya. Sementara dalam perencanaan karier, masukkan, saran, dan pendapat orang tua sangat diperlukan agar siswa dapat mengambil keputusan perencanaan karier yang matang setelah tamat. Namun, bukan berarti keputusan perencanaan karier siswa terletak pada orang tua, akan tetapi pada siswa itu sendiri. Karena itu, dapat dijelaskan bahwa peran orang tua dapat mempengaruhi perencanaan karier siswa. Faktor kedua, kedisiplinan. Siswa budaya Lembak rata-rata kurang disiplin dalam mematuhi tata tertib di sekolah. Masih ada siswa-siswi terlambat ke sekolah dan mengumpulkan tugas. Siswa kurang disiplin dalam mencari informasi tentang dunia kerja. Ketika guru BK mengajak untuk berdiskusi tentang perencanaan karier, siswa juga sering tidak datang tepat waktu. Bahkan, ada siswa yang di kantin sekolah pada saat jam pelajaran berlangsung. Apabila siswa kurang disiplin, tentu dapat mempengaruhi perencanaan karier. Hal ini dikarenakan siswa dituntut untuk aktif bertanya dan mencari informasi, serta berdiskusi dengan orang tua dan guru BK ketika proses merencanakan karier. Oleh sebab itu, dapat dijelaskan bahwa kurang disiplin dapat mempengaruhi perencanaan karier siswa. Faktor ketiga, komunikasi. Siswa budaya Lembak dalam berkomunikasi, baik dengan guru, maupun dengan teman sebaya sering berbicara dengan nada yang kasar dan keras. Akibatnya, siswa budaya Lembak mengalami kesulitan dalam bergaul dengan teman sebayannya yang bukan dari budaya Lembak. Komunikasi yang tidak baik mengakibatkan siswa budaya Lembak kurang memperoleh informasi, baik dari guru BK, maupun dari teman sebayanya terkait dengan perencanaan karier. Oleh sebab itu, dapat dijelaskan bahwa komunikasi dapat mempengaruhi perencanaan karier siswa. Faktor keempat, tanggung jawab. Siswa budaya Lembak kurang bertanggung jawab terhadap tugas dari gurunya. Siswa terlambat dalam pengumpulan tugas, baik tugas dari guru pelajaran, maupun dari guru BK tentang perencanaan karier siswa. Jadi, dapat dikemukakan bahwa tanggung jawab dapat mempengaruhi perencanaan karier siswa.

Berdasarkan tabel 1 di atas, didapatkan uraian bahwa budaya Lembak, meliputi kurangnya peran orang tua, kurangnya kedisiplinan, kurang baiknya komunikasi, dan kurangnya tanggung jawab. Keempat faktor budaya tersebut menyebabkan perilaku siswa yang mayoritas homogen dan menghasilkan kurang optimalnya perencanaan karier siswa. Berikut ini uraian pembahasan lebih lanjut.

1. Peran Orang tua

Siswa budaya Lembak kurang mendapatkan perhatian dan dukungan dari orang tua, orang tua hanya menyediakan biaya pendidikan saja, orang tua tidak ada waktu untuk diskusi dengan baik tentang pendidikan yang sedang ditempuh oleh anak maupun tentang perencanaan karier siswa. Sementara itu, peran orang tua penting terutama dalam perencanaan karier. Seyogyanya orang tua dapat melaksanakan perannya dengan baik, misalnya, meluangkan waktu untuk berdiskusi dengan anak terkait dengan pendidikan yang sedang anak tempuh, begitu juga tak kalah penting diskusi tentang perencanaan karier. Peran orang tua tentu dapat mempengaruhi perencanaan karier siswa.

Hasil penelitian ini memperkuat hasil penelitian yang ada sebelumnya. Hasil penelitian Putra (2018) mengemukakan bahwa bentuk keterlibatan orang tua, yaitu dapat memberikan saran memilih sekolah, memberikan masukkan tentang sikap anak, menyekolahkan anak, memberikan waktu luang, menginformasikan pilihan sekolah, memberi arahan, memahami aspek karier, berdiskusi, mengetahui bakat dan minat, mengecek rapor, mengetahui kebutuhan anak, memiliki harapan karier, mendukung pilihan karier, mengenalkan pekerjaan orang tua, memberikan pengasuhan yang baik, dan mendorong membuat keputusan karier.

Menurut Santrock (dalam Herin \& Sawitri, 2017) bahwa orang tua mempunyai peran dan pengaruh yang penting serta kuat pada pemilihan karier remaja. Orang tua mempengaruhi perilaku karier remaja dalam pengaturan budaya secara kolektif (Sawitri et al., 2014). Peran keluarga mempengaruhi perencanaan karier siswa (Hariko \& Anggriana, 2019). Pada budaya 
Australia dan Thailand, karier ini lebih dipengaruhi karena konsep diri dan gaya pengasuhan orang tua (Hughes, 2011).

Dalam budaya Filipina, pemilihan karier mereka ini umumnya lebih karena pertimbangan latar belakang pekerjaan ayah mereka, pekerjaan ibu, pendapatan keluarga, posisi saudara. Generasi muda di Filipina lebih minat terhadap pengembangan karier yang berhubungan dengan sains, dan kursus lapangan populer, sedangkan bidang yang paling tidak diminati adalah bidang pertanian (Pascual, 2014).

Selanjutnya, Candra (2018) mengemukakan bahwa pengaruh keluarga terhadap perkembangan karier anak terdiri dari dua dimensi, yaitu 1) menyediakan kesempatan pendidikan, keuangan, dan informasi, 2) melalui proses sosial dengan praktik pengasuhan dan hubungan orang tua-anak. Joseph (2012) mengemukakan bahwa keterlibatan orang tua dalam bentuk family involvement (orang tua yang terlibat)/ keterlibatan langsung ditunjukkan dengan beberapa macam aktifitas/ kegiatan yang meliputi kegiatan olah raga, pertemuan dengan pihak sekolah, aktif di dalam kegiatan organisasi orang tua siswa, membantu kemajuan pendidikan, terlibat dalam kegiatan anak, menyediakan informasi, membantu dalam eksplorasi \& pengambilan keputusan karier, memberikan arahan karier.

Dengan demikian, peran orang tua sangat besar dalam perkembangan karier siswa. Contoh yang dapat diambil, seperti seorang anak yang melihat ibunya bekerja di luar rumah dengan memperlihatkan serta menghargai pekerjaannya akan memberikan dampak yang baik bagi pemilihan karier remaja. Hal tersebut juga berlaku bagi seorang ayah. Apabila seorang anak melihat tanggung jawab yang besar pada pekerjaan dan keluarganya akan memberi dampak yang besar terhadap anak dalam perencanaan kariernya.Oleh karena itu, apabila ayah dan ibu yang bekerja mampu menikmati dan menghargai pekerjaanya maka akan berdampak pada anak untuk belajar dalam menghargai pekerjaan seperti orang tuanya (Herin \& Sawitri, 2017).

\section{Kedisiplinan}

Kebiasaan siswa budaya Lembak kurang disiplin dalam kehidupan sehari-hari, kebiasaan itu terbawa di lingkungan sekolah. Rata-rata siswa-siswi budaya Lembak datang terlambat ke sekolah, sering ke ke kantin pada saat jam kegiatan belajar berlangsung. Selain itu siswa juga kurang disiplin dalam mengumpulkan tugas-tugas yang diberikan oleh guru mata pelajaran, siswa memiliki sikap yang kurang begitu mengindahkan apa yang disampaikan oleh guru. Hal yang sama juga terjadi pada saat guru BK mengajak siswa-siswi untuk berdiskusi terkait dengan perencanaan karier. Siswa sering menganggap bahwa perencanaan karier belum begitu penting baginya. Akhirnya, rata-rata siswa budaya Lembak tidak mengikuti kegiatan tersebut. Kebiasaan siswa budaya Lembak kurang disiplin dapat mempengaruhi perencanaan karier siswa.

Sesuai dengan hasil penelitian Permadi (2016) yang mengemukakan bahwa terdapat siswa yang kurang disiplin dan sering menunda dalam hal persiapan karier akan berpengaruh dalam optimalnya perencanaan karier. Hal ini melengkapi penelitian sebelumnya. Hasil prestasi akademik sebagai pertimbangan perencanaan karier (Pascual, 2014). Latar belakang, pribadi, dan lingkungan mempengaruhi perencanaan karier remaja putri (Novakovic \& Fouad, 2013). Atlet dengan sikap disiplin memprediksi sikap perencanaan karier mereka (Tyrance et al., 2013).

Disiplin menjadi salah satu aspek yang penting untuk mencapai kesuksesan dan hal tersebut tidak dapat dilakukan secara instan. Untuk suskes, dibutuhkan usaha \& tekad yang kuat, sehingga mencapai pribadi yang disiplin. Melalui disiplin mampu membawa siswa untuk lebih mengikuti proses belajar dengan baik dan efektif (Reski et al., 2017). Dengan demikian, siswa dapat terbentuk menjadi pribadi yang lebih baik, serta memberikan kesadaran dan kepedulian diri pada kesuksesan hidup dengan memulai langkah awal dalam perencanaan kariernya.

\section{Komunikasi}

Kebiasaan siswa budaya Lembak berkomunikasi dengan nada dan intonasi yang keras, baik dengan guru, maupun dengan teman sebaya. Hal ini membuat siswa budaya Lembak kurang dapat bergaul dengan teman-teman yang bukan dari budaya Lembak. Hal ini mengakibatkan keterbatasan dalam bergaul. Komunikasi pun menjadi sulit dilakukan, terutama dalam komunikasi terkait dengan informasi tentang perencanaan karier. Komunikasi dapat mempengaruhi perencanaan karier siswa. Ferry (dalam Kaneez \& Medha, 2018) menunjukkan aspek yang dapat 
mempengaruhi perencanaan karier siswa, yaitu aspek budaya itu sendiri, konteks sosial keluarga, dan konteks sosial masyarakat. Selanjutnya, hasil penelitian Watson, stead, dan De Jager (dalam H. Sulusyawati \& Sari, 2019) menunjukkan bahwa pengaruh budaya mempengaruhi pilihan karier mahasiswa.

Selain itu, komunikasi juga mampu membentuk siswa menjadi pribadi yang lebih saling pengertian, memelihara kasih sayang, menumbuhkan persahabatan, dan mengembangkan karier (Sari, 2017). Melalui komunikasi akan membentuk persepsi individu sehingga dengan komunikasi yang baik akan adanya hubungan yang baik pada pengembangan kariernya (Siregar \& Hardjo, 2013).

\section{Tanggung Jawab}

Siswa budaya Lembak mayoritas kurang bertanggung jawab terhadap kewajiban sebagai siswa. Rata-rata siswa mengabaikan tanggung jawab yang di berikan guru dengannya, baik yang diberikan oleh guru mata pelajaran, maupun dari guru BK. Kalaupun dikumpulkan sering tidak tepat waktu. Pekerjaan rumah dikerjakan asal-asalan di sekolah. Tugas dari Guru BK terkait dengan perencanaan karier juga sering diabaikan. Padahal, perencanaan karier siswa diperlukan adanya rasa bertanggung jawab. Sebelum memilih jurusan yang diinginkan, siswa seharusnya memikirnya dengan matang \& dapat dipertanggung jawabkan.

Kurang bertanggung jawab tentu dapat mempengaruhi perencanaan karier. Correll (Opier, 2020) menunjukkan bahwa aspek gender seseorang sebagai variabel budaya mempengaruhi pengambilan keputusan karier yang diinginkan. Berdasarkan penelitian longitudinal (Rogers \& Creed, 2011) tentang perencanaan \& eksplorasi karier remaja menggunakan kerangka teori karier kognitif sosial didapatkan hasil bahwa kepribadian dan dukungan lingkungan mempengaruhi efikasi diri. Dari sini kemudian, remaja dapat diprediksi tujuan perencanaan kariernya. Penelitian (Rogers \& Creed, 2011) juga membahas adanya faktor kontekstual dan variabel masa lalu (biografi) remaja mempengaruhi arah perubahan karier seseorang.

Bukti-bukti ilmiah menunjukkan bahwa budaya mempengaruhi pemilihan karier individu. Hal ini diuraikan pada penelitian-penelitian ini. Gunkel et al. (2013) meneliti pada seribu delapan ratus siswa dan diperoleh informasi budaya nasional mempengaruhi perencanaan, adaptasi, optimisme karier, dan pengetahuan yang berhubungan dengan karier. Identitas sosial budaya mempengaruhi pilihan karier mahasiswa pascasarjana (Haley et al., 2014). Pada konteks pedesaan di Virginia, budaya mempengaruhi siswa sekolah menengah untuk bisa merintis karier dimulai dengan kuliah di Perguruan Tinggi (Carrico et al., 2019). Pemahaman budaya mempengaruhi perencanaan karier tenaga perawat di Melbourne, Australia (Gower et al., 2018).

Studi lintas budaya dari Andre et al. (2019) di Amsterdam, Netherlands menghasilkan data bahwa remaja akan menginvestasikan waktunya untuk belajar dan merencanakan karier ketika mereka dimotivasi tentang masa depan dan suatu tantangan. Penelitian pada latar belakang budaya Kanada oleh Arthur \& Flynn (2011) menyebutkan bahwa Kanada memiliki peluang kerja dan standar hidup yang tinggi, sehingga siswa internasional mengejar karier di sana. Pada latar budaya Queensland, Australia, sebuah studi Robinson et al. (2016) menghasilkan data bahwa siswa yang pernah magang di perhotelan, menginginkan untuk pindah berkarier ke bidang pariwisata. Mereka menganggap industri pariwisata lebih menjanjikan daripada perhotelan. Latar belakang sekolah siswa mempengaruhi perencanaan karier siswa. Siswa dari sekolah kejuruan memiliki perencanaan karier lebih tinggi daripada siswa yang bersekolah di sekolah umum di Carolina Selatan (Mobley et al., 2017).

Namun, hal ini bertentangan dengan hasil penelitian Akosah-Twumasi et al. (2018) dari Singapura. Akosah-Twumasi et al. (2018) mencoba meneliti budaya di seluruh dunia melalui database artikel jurnal yang diterbitkan dari 1997-2018. Hasil penelitian membuktikan bahwa ternyata warisan budaya bisa bertentangan dengan kepentingan pribadi generasi muda dalam memilih karier. Remaja lebih banyak dipengaruhi oleh minat pribadi, kedua dipengaruhi oleh harapan keluarga dalam memilih karier. Sementara itu, remaja yang merantau di negara lain, lebih termotivasi dalam pengambilan keputusan karier mereka.

Temuan penelitian berimplikasi pada ilmu konseling. Perencanaan karier siswa tidak lepas dari faktor budaya daerah. Akan tetapi, hal ini tidak selalu linier. Siswa juga memiliki 
preferensi pribadi dalam merencanakan karier. Melihat hasil penelitian di atas, implikasi bagi guru BK adalah memotivasi siswa dalam merencanakan karier sejak dini. Selain itu, guru BK dapat membantu mereduksi kebiasaan negatif siswa akibat faktor budaya setempat dengan harapan agar tidak mempengaruhi perencanaan karier.

Keterbatasan temuan penelitian berlaku pada budaya Lembak. Pada budaya lain, hasil penelitian bisa berbeda. Saran untuk penelitian lanjutan, yaitu: peneliti lain dapat meneliti secara kuantitatif hasil untuk melengkapi data kualitatif berikut. Peneliti lain juga dapat meneliti perencanaan karier siswa dengan variabel budaya yang berbeda.

\section{Simpulan}

Berdasarkan hasil dan pembahasan yang dijelaskan sebelumnya, dapat disimpulkan bahwa pengaruh budaya Lembak terhadap perencanaan karier siswa, yaitu kurangnya peran orang tua, kurangnya kedisiplinan, kurang baiknya komunikasi, dan kurangnya tanggung jawab siswa. Agar siswa dapat mempersiapkan perencanaan karier yang baik, diharapkan siswa mendapat peran dan dukungan dari orang tua. Siswa juga harus disiplin dalam mencari informasi terkait dengan jurusan yang akan dipilih ketika memasuki perguruan tinggi atau memasuki dunia kerja yang diinginkan. Siswa diharapkan dapat menjalin komunikasi yang baik, baik dengan orang tua, guru, maupun teman sebaya, agar dapat berdiskusi terkait dengan potensi yang ada dalam diri dengan kecocokan jurusan yang akan dipilih ketika memasuki perguruan tinggi atau dunia kerja yang diinginkan. Selain itu, diharapkan agar siswa bertanggung jawab terhadap keputusan yang akan diambil, baik jurusan yang akan dipilih memasuki perguruan tinggi, maupun dunia kerja yang akan dipilih. Untuk mewujudkan agar siswa memiliki perencanaan karier yang matang, diharapkan adanya peran guru BK dalam membantu siswa-siswi di sekolah khususnya siswa budaya Lembak.

\section{Ucapan Terima Kasih}

Terima kasih disampaikan kepada Lembaga Penelitian dan Pengabdian Masyarakat (LPPM) Universitas Prof. Dr. Hazairin, SH Bengkulu, yang telah memfasilitasi dalam menyediakan forum diskusi penyusunan proposal. Terima kasih disampaikan kepada Kementerian Pendidikan dan Kebudayaan Lembaga Layanan Pendidikan Tinggi Wilayah II yang telah memberikan Pendanaan Penelitian. Terima kasih disampaikan kepada Diknas Pendidikan Provinsi Bengkulu yang telah memberikan rekomendari izin penelitian. Terima kasih disampaikan kepada Sekolah SMA Negeri 9 Kota Bengkulu yang telah memberikan izin untuk melakukan penelitian. Ucapan Rasa Syukur kami sampaikan kepada Allah SWT.

\section{Daftar Rujukan}

Ahmad, R. (2013). Dasar-dasar Bimbingan dan Konseling. UNP Press.

Akosah-Twumasi, P., Emeto, T. I., Lindsay, D., Tsey, K., \& Malau-Aduli, B. S. (2018). A systematic review of factors that influence youths career choices-the role of culture. Frontiers in Education, 3, 58.

Aminurrohim, A. W., Saraswati, S., \& Kurniawan, K. (2014). Survei faktor-faktor penghambat perencanaan karir siswa. Indonesian Journal of Guidance and Counseling: Theory and Application, 3(2).

Andre, L., Peetsma, T. T. D., van Vianen, A. E. M., in de Wal, J. J., Petrović, D. S., \& Bunjevac, T. (2019). Motivated by future and challenges: A cross-cultural study on adolescents' investment in learning and career planning. Journal of Vocational Behavior, 110, 168-185.

Arthur, N., \& Flynn, S. (2011). Career development influences of international students who pursue permanent immigration to Canada. International Journal for Educational and Vocational Guidance, 11(3), 221-237.

Candra, S. (2018). Pelaksanaan Parenting bagi Orang Tua Sibuk dan Pengaruhnya bagi Perkembangan Anak Usia Dini. ThufuLA: Jurnal Inovasi Pendidikan Guru Raudhatul Athfal, 5(2), 267-287.

Carrico, C., Matusovich, H. M., \& Paretti, M. C. (2019). A qualitative analysis of career choice pathways of college-oriented rural central Appalachian high school students. Journal of Career Development, 
46(2), 94-111.

Fauziyah, A., Yusuf, S., \& Alian, A. (2020). Peranan Letnan I Nawawi Manaf Di Bengkulu Pada Masa Revolusi Fisik Tahun 1945-1949. Agastya: Jurnal Sejarah Dan Pembelajarannya, 10(1), 67-88.

Gower, S., Dantas, J. A. R., Duggan, R., \& Boldy, D. (2018). The influence of international nursing placements on cultural competence and career planning. Australian Nursing and Midwifery Journal, 26(1), 41.

Gunkel, M., Schlägel, C., Langella, I. M., Peluchette, J. V, \& Reshetnyak, E. (2013). The influence of national culture on business students' career attitudes-an analysis of eight countries. German Journal of Human Resource Management, 27(1), 47-68.

Hajad, M., \& Nanik, S. (n.d.). ETNOBOTANI TUMBUHAN OBAT OLEH MASYARAKAT SUKU LEMBAK KELURAHAN SUKARAMI KECAMATAN SELEBAR KOTA BENGKULU. Fakultas Matematika Dan IImu Pengetahuan Alam UNIB.

Haley, K. J., Jaeger, A. J., \& Levin, J. S. (2014). The influence of cultural social identity on graduate student career choice. Journal of College Student Development, 55(2), 101-119.

Hanggara, G. S. (2016). Keefektifan "Proses Guru" Sebagai Teknik Bimbingan Kelompok untuk Meningkatkan Kemampuan Pengambilan Keputusan Karier Siswa SMK. Jurnal Kajian Bimbingan Dan Konseling, 1(4), 148-157.

Hariko, R., \& Anggriana, T. M. (2019). Reviewing the role of families in student career planning. Konselor, $8(1), 6-11$.

Heer, E. L., Cramer, s. H., \& Niles, S. G. (2004). Career Guidance and Counseling Through the Life Span: Sistematic approaches. Allyn and Bacon.

Herin, M., \& Sawitri, D. R. (2017). Dukungan orang tua dan kematangan karir pada siswa SMK program keahlian tata boga. Empati, 6(1), 301-306.

Hughes, C. (2011). The influence of self-concept, parenting style and individualism-collectivism on career maturity in Australia and Thailand. International Journal for Educational and Vocational Guidance, 11(3), 197-210.

Joseph, L. L. (2012). The impact of family influence and involvement on career development.

Julia, J., \& Afandi, M. (2020). Efektivitas Teknik Mind Mapping Dalam Layanan Bimbingan Kelompok Untuk Meningkatkan Kemampuan Perencanaan Karir Siswa. Jurnal Administrasi Pendidikan \& Konseling Pendidikan, 1(2), 106-113.

Kaneez, B.-S., \& Medha, K. (2018). Factors influencing grade 10 students' career choice in Mauritius. DEVELOPMENT, 7(2).

Kaswan. (2014). Career Development: Pengembangan karier untuk mencapai kesuksesan dan kepuasan. CV. Alfabeta.

Kurnia, M., Amir, H., \& Handayani, D. (2020). ISOLASI DAN IDENTIFIKASI BAKTERI ASAM LAKTAT DARI MAKANAN TRADISIONAL SUKU REJANG DI PROVINSI BENGKULU:“LEMEA.” Alotrop, 4(1).

Kurniasari, R., Sofah, R., \& Harlina, H. (2016). Kemampuan perencanaan karir siswa Kelas $X$ di SMA Negeri 3 Palembang. Sriwijaya University.

Mahdi, I., Miinuddin, M., \& Mike, E. (2019). Mengaktualisasikan Kearifan Lokal Suku Rejang Bengkulu Dalam Peraturan Daerah (PERDA).

Masaong, A. K. (2012). Pendidikan karakter berbasis multiple intelligence. Jurnal Konaspi VII Universitas Negeri Yogyakarta.

Mobley, C., Sharp, J. L., Hammond, C., Withington, C., \& Stipanovic, N. (2017). The influence of careerfocused education on student career planning and development: A comparison of CTE and non-CTE students. Career and Technical Education Research, 42(1), 57-75.

Novakovic, A., \& Fouad, N. A. (2013). Background, personal, and environmental influences on the career planning of adolescent girls. Journal of Career Development, 40(3), 223-244.

Opier, N. M. (2020). Pengaruh Locus Of Control dan peran gender terhadap pengambilan keputusan karir siswa kelas XI dan XII SMAS Diponegoro Tumpang. Universitas Islam Negeri Maulana Malik Ibrahim.

Pascual, N. T. (2014). Factors affecting high school students' career preference: A basis for career planning program. International Journal of Sciences: Basic and Applied Research, 16(1), 1-14.

Permadi, N. E. (2016). Masalah-Masalah yang Dihadapi Peserta Didik dalam Perencanaan Karir dan Implikasinya terhadap Pelayanan Bimbingan Karir. Jurnal Penelitian Bimbingan Dan Konseling, 1(2).

Prasetiawan, H. (2016). Peran Bimbingan dan Konseling dalam Pendidikan Ramah Anak terhadap Pembentukan Karakter Sejak Usia Dini. Jurnal CARE (Children Advisory Research and Education), $4(1), 50-60$.

Putra, A. K. (2018). Keterlibatan orang tua dalam perencanaan karir anak usia SMP di Dusun Jamburejo. Jurnal Riset Mahasiswa Bimbingan Dan Konseling, 4(9), 501-511.

REFISRUL, N. F. N. (2019). Fungsi Lemang dalam Upacara Perkawinan Suku Besemah di Kabupaten Kaur Provinsi Bengkulu. Jurnal Penelitian Sejarah Dan Budaya, 5(2), 235-256. 
Reski, N., Taufik, T., \& Ifdil, I. (2017). Konsep diri dan kedisiplinan belajar siswa. Jurnal EDUCATIO: Jurnal Pendidikan Indonesia, 3(2), 85-91.

Robinson, R. N. S., Ruhanen, L., \& Breakey, N. M. (2016). Tourism and hospitality internships: influences on student career aspirations. Current Issues in Tourism, 19(6), 513-527.

Rogers, M. E., \& Creed, P. A. (2011). A longitudinal examination of adolescent career planning and exploration using a social cognitive career theory framework. Journal of Adolescence, 34(1), 163172.

Salleh, A. M. M., Omar, K., Aburumman, O. J., Mat, N. H. N., \& Almhairat, M. A. (2020). The impact of career planning and career satisfaction on employee's turnover intention. Entrepreneurship and Sustainability Issues, 8(1), 218.

Sari, A. A. (2017). Komunikasi antarpribadi. Deepublish.

Sawitri, D. R., Creed, P. A., \& Zimmer-Gembeck, M. J. (2014). Parental influences and adolescent career behaviours in a collectivist cultural setting. International Journal for Educational and Vocational Guidance, 14(2), 161-180.

Sharf, R. S. (2010). Applying Career Development Theory to Counseling. Edition 5 TH Pacific Grove. University of Delaware: Brooks/Cole Cengage Learning.

Siregar, C. Y., \& Hardjo, S. (2013). Hubungan komunikasi interpersonal dan persepsi pengembangan karir dengan kepuasan kerja. Analitika: Jurnal Magister Psikologi UMA, 5(1), 11-17.

Subianto, J. (2013). Peran keluarga, sekolah, dan masyarakat dalam pembentukan karakter berkualitas. Edukasia: Jurnal Penelitian Pendidikan Islam, 8(2).

Sugiyono. (2010). Metode Penelitian Kuantitatif, Kualitatif, dan R\&D. CV. Alfabeta.

Sugiyono. (2018). Metode Penelitian Kuantitatif, Kualitatif, dan R\&D. Alfabeta.

Sulusyawati, H. \& J. (2019). Pengaruh Budaya Serawai Terhadap Perencanaan Karier Siswa di SMA Negeri 9 Kota Bengkulu.

Sulusyawati, H., \& Juwanto, J. (2020). Malay Culture Effect on Career Planning Student SMA City 9 Bengkulu. Islamic Counseling: Jurnal Bimbingan Dan Konseling Islam, 4(2), 237-246.

SULUSYAWATI, H., \& MELATI, M. (2019). PENGARUH BUDAYA REJANG TERHADAP PERENCANAAN KARIER SISWA DI SMA NEGERI 9 KOTA BENGKULU. Psikodidaktika: Jurnal IImu Pendidikan, Psikologi, Bimbingan Dan Konseling, 4(2), 27-35.

Sulusyawati, H., \& Sari, W. K. (2019). Potret Perencanaan Karier Siswa Budaya Rejang di SMA Negeri 9 Kota Bengkulu. Indonesian Journal of Guidance and Counseling: Theory and Application, 8(2), 114118.

Sulusyawati, H., Yusuf, A. M., \& Daharnis, D. (2017). Perencanaan karier siswa di SMA ditinjau dari status sosial ekonomi, jenis kelamin, dan jurusan. Bikotetik (Bimbingan Dan Konseling: Teori Dan Praktik), $1(1), 8-14$.

Tyrance, S. C., Harris, H. L., \& Post, P. (2013). Predicting positive career planning attitudes among NCAA Division I college student-athletes. Journal of Clinical Sport Psychology, 7(1), 22-40.

W.S, Winkel \& Hastuti, S. (2013). Bimbingan dan Konseling di Institusi Pendidikan. Media Abadi.

Yusuf, A. M. (2002). Kiat Sukses dalam Karier. Ghalia.

\section{Competing interests:}

The authors declare that they have no significant competing financial, professional or personal interests that might have influenced the performance or presentation of the work described in this manuscript. 